\title{
Penile Incarceration with Metallic Foreign Bodies: Management and Review of Literature
}

\author{
Sameer Trivedi Amit Attam Arun Kerketa Navin Daruka \\ Bharat Behre Abhinav Agrawal Sudhir Rathi U.S. Dwivedi \\ Department of Urology, Institute of Medical Sciences, Banaras Hindu University, Varanasi, India
}

\section{Key Words}

Penile strangulation - Constricting objects .

Penile amputation

\begin{abstract}
Introduction: Penile strangulation from constricting metallic objects disorders is an uncommon urological emergency which requires prompt intervention to prevent complications. The treatment modalities are diverse and characterized by lack of consensus. Material and Methods: Three cases with penile incarceration due to constricting metallic objects who presented to our department were included in this study. All 3 patients required different management options highlighting the diversity of clinical presentation and need for customization of treatment as per the clinical scenario. Results: The 3 patients required different approach for treatment. First patient could be managed by degloving of penile skin while second patient required mechanical removal of the foreign body and debridement of local necrotic tissues. The third patient had to undergo excision of gangrenous penile skin and skin grafting. Conclusion: The study emphasizes the diversity of clinical presentations and the need for employing different surgical techniques to achieve the desired results.

Copyright $\odot 2013$ S. Karger AG, Basel
\end{abstract}

\section{KARGER}

Fax +4161306 1234

E-Mail karger@karger.ch

www.karger.com
(C) 2013 S. Karger AG, Basel

1015-9770/13/0071-0045\$26.00/0

Accessible online at:

www.karger.com/cur

\section{Introduction}

Penile incarceration due to application of foreign bodies is a historically recognized phenomenon with the first case reported in 1755 [1]. Yet, few reports about this peculiar entity are available in the literature and most of these are single case reports. The reported motives for placing an incarcerating object include attempted enhancement of sexual performance and heightening of sexual sensation and orgasm [2], self-treatment of erectile dysfunction [3-5] and psychiatric disorders $[6,7]$ in adults, while in the pediatric population, this maneuver has been attempted for prevention of enuresis [8]. A plethora of objects have been reported like nuts, washers, plastic and steel rings, bottles, rubber bands, bottlenecks, ball-bearings and wedding rings.

These constricting objects, when placed over the flaccid or partially erect penis, often lead to secondary edema resulting in inability to remove them subsequently. The resultant incarceration causes a potential penile compartment syndrome with an initial venous and lymphatic outflow obstruction distal to the foreign object followed by arterial inflow obstruction, ultimately resulting in tissue ischemia and necrosis $[9,10]$.

Penile strangulation is a genuine urologic emergency which necessitates prompt measures to remove the constricting foreign body and decompress the involved tissues. Literature is replete with techniques to achieve this objective; however, owing to the diverse objects used and the sundry clinical presentations, no single surgical maneuver can be deemed appropriate for all cases.

Sameer Trivedi

Department of Urology, Institute of Medical Sciences

Banaras Hindu University,

IN-221005 Varanasi (India)

E-Mail drsameertrivedi@gmail.com 
We present our experience with 3 cases of penile incarceration highlighting the diversity of clinical scenarios and the need for use of different techniques to deal with different dimensions of this unusual clinical entity.

\section{Case Report}

\section{Case One}

A 35-year-old healthy male presented with complaints of progressive pain and swelling over the penis. Detailed history revealed placement of a metallic nut over the root of penis 8 hours back for the purpose of sexual gratification. Repeated attempts by the patient to remove the object had failed. Physical examination revealed a grossly edematous penis with hyperesthesia, dusky discoloration and cool penile skin (fig. 1). The base of the penile shaft was encircled by a $2.5 \times 1 \mathrm{~cm}$ sturdy metallic nut with an outer diameter of $6 \mathrm{~cm}$ and inner diameter of $4 \mathrm{~cm}$. There was no breach in the penile skin beneath the constricting object and the scrotum and testes were normal. Attempts to slip off the object by manual decompression did not succeed. Manual ring cutter was unsuitable because of the sturdiness of the metallic object. Motorized tools like Dremmel rotating saw were unavailable in the operation theater. A circumferential degloving incision was made over the coronal sulcus and aided by constant compression and release of collected venous and lymphatic fluid, it was possible to decompress the penile edema and slip off the offending object without the need for more aggressive measures (fig. 2). The penile skin and shaft was wrapped in warm saline soaked gauze for 10 minutes and viability of the penile skin was confirmed before completing the circumcision like closure of the wound. The patient did not complain of any voiding difficulty in the postoperative period and was allowed to void normally without the need for an indwelling catheter. The patient was discharged from the hospital within 24 hours after a psychiatric consultation and inspection of the wound. The patient was followed-up at 1 week, 1 month and 3 months. The wound healing was satisfactory and patient had normal erectile function with good urinary flow rate on uroflowmetry.

\section{Case Two}

A 48-year-old male presented with complaints of persistent penile pain and swelling for last 14 hours. On history, it became apparent that the patient had slipped a gold plated metallic ring attached to a metallic chain over the penis for auto-erotic purposes. As per the patient, he had successfully performed this maneuver in the past on many occasions. On local examination, a $5 \mathrm{x}$ $5 \mathrm{~mm}$ constricting metallic ring with an outer diameter of $6 \mathrm{~cm}$ and an inner diameter of $5 \mathrm{~cm}$ with an attached metallic chain about $15 \mathrm{~cm}$ in length, was found encircling the root of penis with gross edema of the distal penile shaft and erythematous penile skin, which was warm on palpation and hypersensate (fig. 3). The underlying penile skin at the site of the constricting ring revealed ulceration and necrosis with presence of slough at the margins. Manual decompression and attempts to remove the constricting ring did not succeed. In the operation theater, a manual stainless steel ring cutter was used to cut the metallic ring on dorsal and ventral aspects, 180 from each other, and achieve decompression of the penis. The underlying skin erosion was treated by debridement and excision of the necrotic tissues followed by primary suture closure. The patient required insertion of Foley's catheter for 48 hours following complaints of difficulty in voiding in the postoperative period. The patient was discharged on third postoperative day after a successful trial of voiding and satisfactory surgical wound. On subsequent follow-up at 1, 4 and 12 weeks, the erectile function and the urinary flow rates on uroflowmetry were normal. The psychiatric evaluation of the patient revealed severe depression and appropriate treatment and counseling were instituted accordingly.

\section{Case Three}

A 38-year-old male patient was referred to the urology outpatient department with history of removal of a strangulating foreign body from the base of penis 72 hours ago at a district hospital. The offending object was a steel ring and the mode of removal was by means of a manual ring cutter. The duration of incarceration of penis before achieving decompression was 30 hours. Despite the removal of the constricting object there was a progressive necrosis and blackening of the penile skin over the past 72 hours. On examination, the skin overlying the base of penis revealed an ulcer over the dorsum which involved nearly half of the circumference of the shaft with unhealthy margins (fig. 4). The distal penile skin was dusky and cold with multiple areas of necrosis and superficial skin ulcers. The patient was treated conservatively with broad spectrum parenteral antibiotics, debridement of necrotic tissues, local wound toilet and supportive treatment including low molecular weight heparin in order to limit the ischemic damage. However, even after 48 hours, the penile skin necrosis progressed unabated and more than $3 / 4$ of the penile skin was necrotic and gangrenous. After consultation with plastic surgeon, a complete debridement of the gangrenous penile skin was performed and an unmeshed, unexpanded split skin thickness graft was applied for covering the resultant defect. The graft thickness was $0.3 \mathrm{~mm}$ and meshing was performed in a 1:1 ratio with the meshed slits oriented transversely without expansion and the graft juncture located on the ventral surface in zigzag fashion. An elective suprapubic catheter was placed for 5 days postoperatively. The wound was inspected and dressed periodically and the patient was discharged on 7 th postoperative day. Graft take, appearance, and sexual and voiding functions were assessed postoperatively. The postoperative recovery was satisfactory with normal take of the graft and no voiding difficulty. The patient could resume normal sexual intercourse after 6 weeks but has reported loss of sensation over the graft site till the last follow-up at 3 months.

\section{Discussion}

Penile strangulation by constricting devices is an uncommon entity with few reported cases in the literature [11]. The most common reason for placement of these constricting objects that encircle the penis is auto-eroticism. The resultant venous congestion augments penile length and girth. However, prolonged application of such objects leads to inability to remove them after development of edema from venous congestion and obstruction 


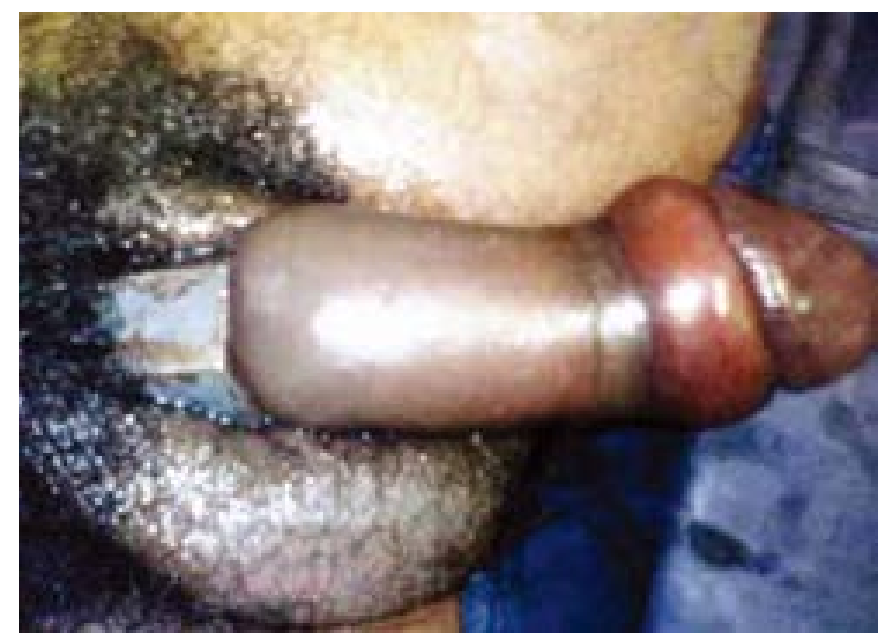

Fig. 1. Physical examina -tion revealed a grossly edematous penis with hyperesthesia, dusky discoloration and cool penile skin.

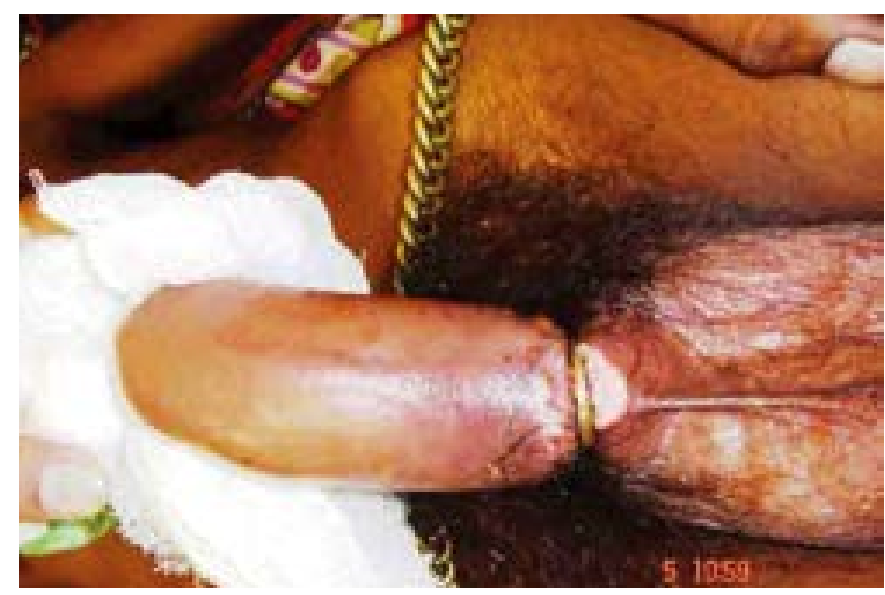

Fig. 3. Constricting metallic ring with an outer diameter of $6 \mathrm{~cm}$ and an inner diameter of $5 \mathrm{~cm}$ with an attached metallic chain about $15 \mathrm{~cm}$ in length.

of the lymphatic drainage and can result in skin erosion, ischemic necrosis, infarction, and gangrene of the penile skin. The associated embarrassment is often the cause of delayed presentation with consequent sequelae. The choice of object and the resulting clinical consequences are widely variable and therefore the treatment options have to be individualized as per the clinical scenario. But

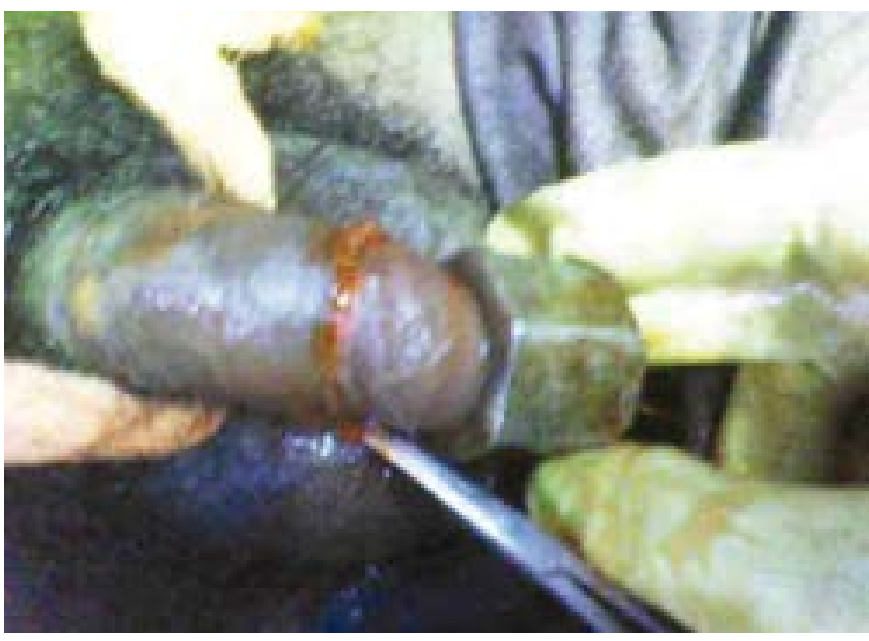

Fig. 2. A circumferential degloving incision was made over the coronal sulcus and aided by constant compression and release of collected venous and lymphatic fluid.

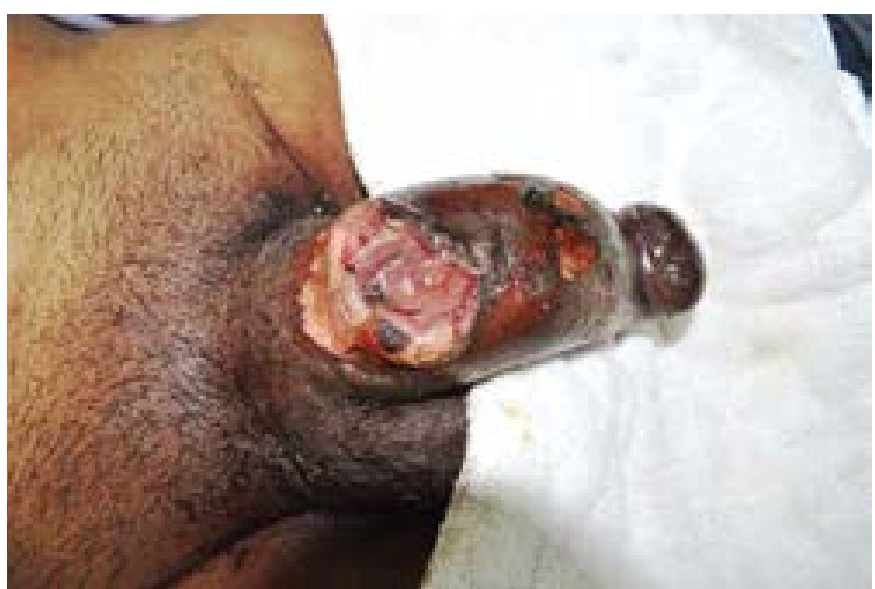

Fig. 4. On ex -amination, the skin overlying the base of penis revealed an ulcer over the dorsum which involved nearly half of the circumference of the shaft with unhealthy margins.

in almost all of these cases, the presentation is as a genuine urological emergency requiring prompt intervention, as the consequences of penile strangulation can be devastating in form of urethro-cutaneous fistula, penile skin necrosis, penile fibrosis, and complete gangrene of penis $[12,13]$. A thorough history including duration of incarceration and focused physical examination to assess type 
and composition of the constricting object, local tissue temperature, color, sensation, edema, voiding difficulty, and viability of affected tissues is vital before deciding upon the treatment. Few reports have recommended imaging of penile and testicular blood flow before removal of the constricting object, but this is likely to prolong the duration of strangulation without altering the primary treatment i.e. removal of the offending object and restoration of vascular and lymphatic circulation. Broad spectrum antibiotics should be administered at the earliest and laboratory tests including a complete hemogram and urinalysis and urine culture should be obtained.

The purported motives for placement of constricting objects are almost always sexual in nature in adult population [2, 3, 5, 7, 14-17]. All the 3 patients in this series placed these metallic objects for sexual gratification. Few of the published reports have analyzed the psychiatric status of these patients $[7,14,16]$ and it is likely that a more detailed evaluation of cognitive state of these patients by trained psychologists may reveal underlying contributory factors. All the 3 patients in our series were assessed by a psychiatrist and one patient having severe depression was put on appropriate therapy while another patient was advised regular counseling sessions for psychological erectile dysfunction.

A grading scale for penile incarceration has been proposed by Bhat et al. [14]: grade 1 - distal edema only; grade 2 - distal edema, skin and urethral trauma, corpus spongiosum compression, decreased penile sensation; grade 3 - skin and urethral trauma, no distal sensation; grade 4 - separation of corpus spongiosum, urethral fistula, corpus cavernosum compression, no distal sensation; and, grade 5 - gangrene, necrosis, or distal penile amputation. A revised and simpler grading system was proposed by Silberstein et al. [16], in which penile incarceration injuries were classified into low and high grade injuries depending upon the need for subsequent surgical intervention after the removal of offending foreign object. The reported incidence of high grade injuries in the published studies using this grading system was $14.2 \%$ as compared to $67.2 \%$ for low grade injuries. Two of the 3 cases in our series did not require any subsequent procedures and can be classified as low grade injuries while 1 patient who underwent delayed skin grafting can be considered to have a high grade injury. The incidence of high grade injuries has been reported to be higher with non-metallic objects as compared to metallic objects (77.7 vs. $22.2 \%$ ) [16]. The probable cause for this may lie in the fact that non-metallic objects are more elastic and can produce more severe constriction on the penis.
The reported incidence of voiding difficulty in penile strangulation injuries is widely variable and some of the published reports have neglected to mention this finding. In a review of published reports, Silberstein et al. [16] reported normal voiding in $37.7 \%$, urinary retention in $19.6 \%$ and insufficient data in $42.6 \%$ patients. In our series, 1 patient needed catheterization following complaints of voiding difficulty while another patient underwent elective suprapubic catheterization following penile skin grafting procedure. The issue of choosing between per-urethral catheter and suprapubic catheter is contentious. While suprapubic catheter may be easier to perform in a setting of urethral edema/trauma and may theoretically prevent further injury to the urethra [16], the placement of urethral catheters has not been shown in many reports to be difficult or associated with subsequent complications [7,14,18].

The duration of incarceration plays an important role in the severity of the clinical presentation. Silberstein et al. [16] reported a higher incidence of high grade injuries when patients presented after 72 hours $(29.1 \%)$ as compared to patients presenting within 72 hours $(0 \%)$. In our series, although all the 3 patients presented within 72 hours, yet one of them sustained a high grade injury (case 3 ) requiring subsequent intervention. Thus, factors other than the duration of injury also appear to have a bearing on the grade of trauma. Nevertheless, prompt removal of the constricting foreign body should be the primary objective of treatment.

Although various techniques for removal of offending objects have been reported, the widely variable clinical presentation and the gamut of objects used preclude any single technique to be universally pertinent $[15,16]$. However, the need for speedy identification and prompt decompression is unanimously recognized. The choice of removal technique is dictated by size, type and composition of the object, duration of strangulation, grade of injury, experience of the surgeon and availability of the equipment [17]. The non-metallic objects like plastic rings and rubber bands can simply be removed by manual cutters except in rare circumstances like PET (polyethylene-terephthalate) bottles which may need more aggressive methods like electric saws [16]. The surgical challenge in grade 1-3 injuries is to remove the device before the onset of penile gangrene. Several case reports have described unsuccessful preliminary attempts before achieving the therapeutic goal of foreign body removal $[5,9,18,19]$. Conventional methods described to remove the incarcerating object include: aspiration of blood from the glans; use of saws, drills and cutters; the 
string technique, and various surgical procedures. The duration and severity of trauma at presentation has a direct bearing on the chosen treatment modality. In general, string techniques and aspiration procedures, alone or more commonly in combination, are suitable for grade 1-3 injuries [7, 20, 21], while use of cutting devices like ring cutters, metal saws, hammer and chisel, drills etc has been described in all grades of injuries with reasonable degree of success $[4,10,14,18]$. Use of electrical cutting devices requires utmost care and safety precautions to avoid iatrogenic injuries. An interposition of a metallic object to prevent the underlying tissues while cutting considerably minimizes the risk of inadvertent injuries. Most commonly utilized objects for this purpose include a malleable retractor [22], tongue depressors [18, 23] and a laryngoscope blade [16]. It is advisable to cut the constricting objects at 2 sites which are diametrically opposite to each other to facilitate easy removal although there are reports in literature where a single incision with a cast spreader has been used with success [10]. Use of surgical techniques is generally required in grade 5 injuries which usually require penile amputation with micro-vascular reconstruction [24-26]. Occasionally, minor surgical procedures can be used with good outcomes in selected patients with lesser grades of injury if suitable cutting instruments are not available. In Patient One of this series, we could obtain successful results with the use of degloving maneuver by a circumcoronal incision. A simple removal of the constricting object and overlooking the underlying devitalized tissues can lead to complications like infection, urethral fistulae, tissue necrosis, prolonged recovery time and even penile amputation. In Patient Three, the patient required subsequent procedures in form of penile skin debridement and skin grafting despite a prior successful removal of the incarcerating foreign body. The penis must be meticulously examined following the removal of the object for signs of ischemia and devitalized skin. Use of color Doppler has been recommended by few authors to confirm vascular patency $[27,28]$. In cases with suspected ischemic damage, intravenous fluorescein injection and examination of the penis under Wood's light at 20 minutes may aid in decision making [10]. In most cases, close monitoring, prevention of infection, penile skin care and heparinization are sufficient to preserve the underlying tissues.

The follow-up data on these patients in the published literature is grossly under-reported mainly on account of the poor patient compliance. The potential complications which can occur include erectile dysfunction, priapism, penile fibrosis, urethral stricture and penile skin necrosis.
Moreover, proper psychiatric evaluation for assessment of behavioral disorders is necessary in all patients to diagnose and manage any underlying cognitive impairment.

\section{Conclusion}

Penile strangulation from constricting metallic objects is an uncommon urological emergency and requires prompt intervention to prevent complications. On the basis of published case reports, it is difficult to lay down strict guidelines about the correct procedure to be used in these cases. Each case is unique in presentation owing to the variables involved the type of object used, the duration of trauma, the individual anatomy and the degree of tissue reaction to the insult. Based on the available resources, the expertise of the treating surgeon and the condition of the affected organ, the management has to be individualized for each patient. The duration of injury is probably the single most important factor affecting the outcome of the treatment. Therefore expedient measures are critical to achieve gratifying outcomes. 


\section{References}

1 Gautier M: Observation d'un entanglement et des testicules et de la verge, occasione par le passage d'un briquette. J Med Chir Pharmacol 1755;3:358.

-2 Schuster G, Stockmal P: Genital incarceration with metal rings: their safe removal. Tech Urol 1999;5:116-118.

-3 Klein FA, Smith MJ: Treatment of incarceration of the penis by tempered steel bushings. J Emerg Med 1987;5:5-8.

4 Kato Y, Kaneko S, Iguchi M, Kurita T: Strangulation of the penis by a ring. Hinyokika Kiyo 1987;33:1672-1675.

$\checkmark 5$ Detweiler MB, Perkins D: Penile incarceration: a wrapping technique. J Emerg Med 2001;20:159-161.

-6 Tiwari VS, Razdan JL, Yadav VN: Strangulation of the penis by a metallic nut. Int Surg 1977;62:558-560.

7 Vahasarja VJ, Hellstrom PA, Serlo W, Kontturi MJ: Treatment of penile incarceration by the string method: 2 case reports. J Urol 1993;149:372-373.

-8 Singh B, Kim H, Wax SH: Strangulation of glans penis by hair. Urology 1978;11:170 172.

-9 Markland C, Merrill D: Accidental penile gangrene. J Urol 1972;108:494-495.

10 Snoy FJ, Wagner SA, Woodside JR, Orgel MG, Borden TA: Management of penile incarceration. Urology 1984;24:18-20.
11 Cassidy DJ, Mador D: Genital incarceration: an unusual case report. Can Urol Assoc J 2010;4:E76-E78.

-12 Perabo FG, Steiner G, Albers P, Muller SC: Treatment of penile strangulation caused by constricting devices. Urology 2002;59:137.

$>13$ Dekou A, Konan PG, Ouegnin GA, Kouame B, Manzan K, De la Torre L, Keo N, Martin $\mathrm{X}$ : Treatment of incarceration of the penis and scrotum. Prog Urol 2006;16:623-624.

14 Bhat AL, Kumar A, Mathur SC, Gangwal KC: Penile strangulation. Br J Urol 1991;68: 618-621

15 Detweiler MB: Penile incarceration with metal objects: A review of procedure choice based on penile trauma grade. Scand J Urol Nephrol 2001;35:212-217.

16 Silberstein J, Grabowski J, Lakin C, Goldstein I: Penile constriction devices: case report, review of the literature, and recommendations for extrication. J Sex Med 2008;5: 1747-1757.

17 Ivanovski O, Stankov O, Kuzmanoski M, Saidi S, Banev S, Filipovski V, Lekovski L, Popov Z: Penile strangulation: two case reports and review of the literature. J Sex Med 2007;4:1775-1780.

$>18$ McLaughlin T, Coyner W: Removal of a strangulating metal bearing from the penis. $\mathrm{J}$ Urol 1989;141:617.

19 Wasadikar PP: Incarceration of the penis by a metallic ring. Postgrad Med J 1997;73:255.
20 Rana A, Sharma N: Masturbation using metal washers for the treatment of impotence: painful consequences. Br J Urol 1994;73:722.

21 Browning WH, Reed DC: A method of treatment for incarceration of the penis. J Urol 1969;101:189-190.

22 Kore RN, Blacklock AR: Ring the fire brigade. Br J Urol 1996;78:948.

23 Kimber RM, Mellon JK: The role of special cutting equipment and corporeal aspiration in the treatment of penile incarceration with a barbell retaining collar. J Urol 2004;172: 975.

$>24$ Lidman D, Danielsson P, Abdiu A, Fahraeus $\mathrm{B}$ : The functional result two years after a microsurgical penile replantation. Case report. Scand J Plast Reconstr Surg Hand Surg 1999; 33:325-328.

25 Harris DD, Beaghler MA, Stewart SC, Freed J R, Hendricks DL: Use of a subcutaneous tunnel following replantation of an amputated penis. Urology 1996;48:628-630.

-26 Sanger J R, Matloub H S, Yousif NJ, Begun FP: Penile replantation after self-inflicted amputation. Ann Plast Surg 1992;29:579_ 584

27 May M, Gunia S, Helke C, Kheyri R, Hoschke B: Penile entrapment in a plastic bottle: a case for using an oscillating splint saw. Int Urol Nephrol 2006;38:93-95.

28 Theiss M, Hofmockel G, Frohmuller HG: Fournier's gangrene in a patient with erectile dysfunction following use of a mechanical erection aid device. J Urol 1995;153:19211922. 